NO RITMO DA MA CULTIVOS DE OSTRAS NORDESTE PARAE 


\section{NO RITMO DA MARÉ: CULTIVOS DE OSTRAS NO NORDESTE PARAENSE ${ }^{1}$}

\section{DIONISO DE SOUZA SAMPAIO}

UNIVERSIDADE FEDERAL DO PARÁ/ CAMPUS BRAGANÇA, INSTITUTO DE ESTUDOS COSTEIROS (IECOS), PARÁ, BRASIL

\section{COLIN ROBERT BEASLEY}

UNIVERSIDADE FEDERAL DO PARÁ/CAMPUS BRAGANÇA, INSTITUTO DE ESTUDOS COSTEIROS (IECOS), PARÁ, BRASIL 
Como profissionais, acompanhamos os cultivos de ostras nos municípios de São Caetano de Odivelas; Curuçá; Maracanã; Salinópolis e Augusto Corrêa no Estado do Pará há mais de dez anos e podemos dizer, com certa propriedade, que nesse universo o ritmo é outro. Bem diferente daquele que levamos em terra firme.

Do cultivo ao prato o caminho percorrido é longo ...

A maré estabelece o horário de trabalho e aí não adianta ter pressa, pois nada se pode fazer a não ser esperar que as águas ditem o ritmo das coisas.

Os momentos de espera são longos ...

E no intervalo do trabalho as vidas que se ali se encontram vão tecendo amizades no entrelace das lanternas e dos travesseiros. As madrugadas são preenchidas com conversa e fumaça dos cigarros enrolados e compartilhados por mãos calejadas.

De sol a sol o cultivo exige do trabalhador muita dedicação. O trabalho é duro, cansativo e o sol não dá trégua. O contato da água salgada com a pele queimada não refresca. Arde, assa, queima...

Aprendi ao longo desse tempo que para me aventurar a estudar esse mundo não bastava apenas observá-lo de longe... Era necessário me deixar envolver pela rotina e pelo tempo do trabalho. Ir lá... Viver também aquela rotina. Conhecer as pessoas, dividir a moradia, repartir a comida.

Os registros fotográficos feitos por mim, Dioniso Sampaio, nos últimos cinco anos são flagrantes do cotidiano de homens e de mulheres que vivem do cultivo das ostras nas seguintes comunidades ribeirinhas: Pererú de Fátima e Vila Pererú (São Caetano de Odivelas); Lauro Sodré e Nazaré do Mocajuba (Curuçá); Nazaré do Seco (Maracanã); Santo Antônio de Urindeua (Salinópolis) e Nova Olinda (Augusto Corrêa).

São retratos que flagram as peculiaridades e a beleza de uma rotina de trabalho desafiadora e cansativa.

Paisagem, trabalho e pessoas se misturam deixando as marcas que humanizam a nossa pesquisa.

A esses trabalhadores nosso respeito, gratidão e admiração.

\section{NOTA}

1 O texto e o ensaio fotográfico fazem parte da minha tese, defendida em julho de 2017, intitulada "Ostreicultura no Nordeste Paraense: Estado atual e perspectivas para sustentabilidade" sob a orientação do Prof. Dr. Colin Robert Beasley do Programa de Pós-Graduação em Biologia Ambiental (PPBA) do Campus Universitário de Bragança. Essa pesquisa foi financiada pelo Conselho Nacional de Desenvolvimento Científico e Tecnológico (CNPq) e pelo extinto Ministério da Pesca e Aquicultura (MPA) e foi realizado sob licença número 28304-1 do Instituto Chico Mendes de Conservação da Biodiversidade (ICMBio).

Dioniso de Souza Sampaio

sampaiods@ufpa.br

Colin Robert Beasley

beasley@ufpa.br 


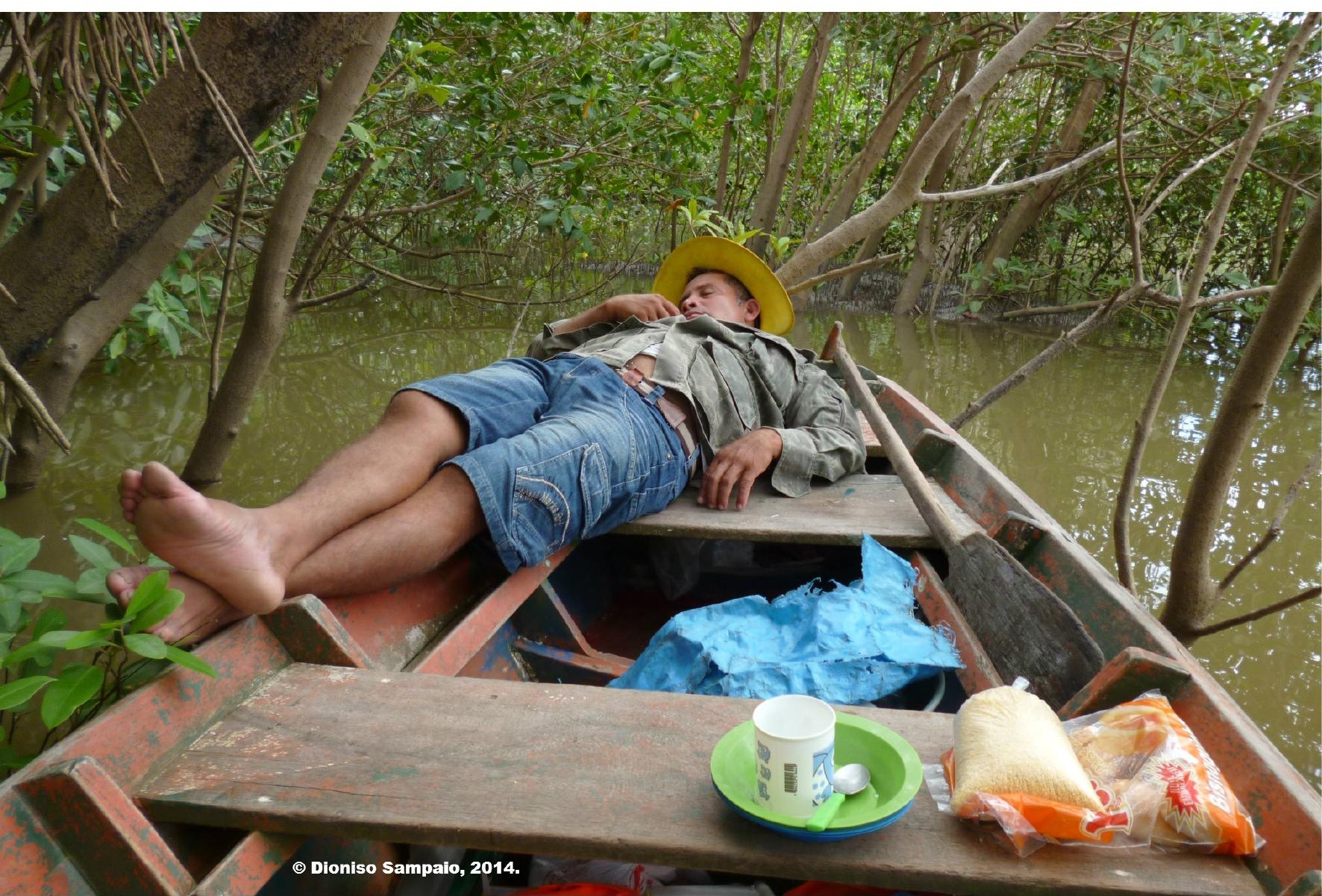

Figura 1 - Esperando a maré baixar - Cultivo em Nazaré do Seco/Maracanã. 


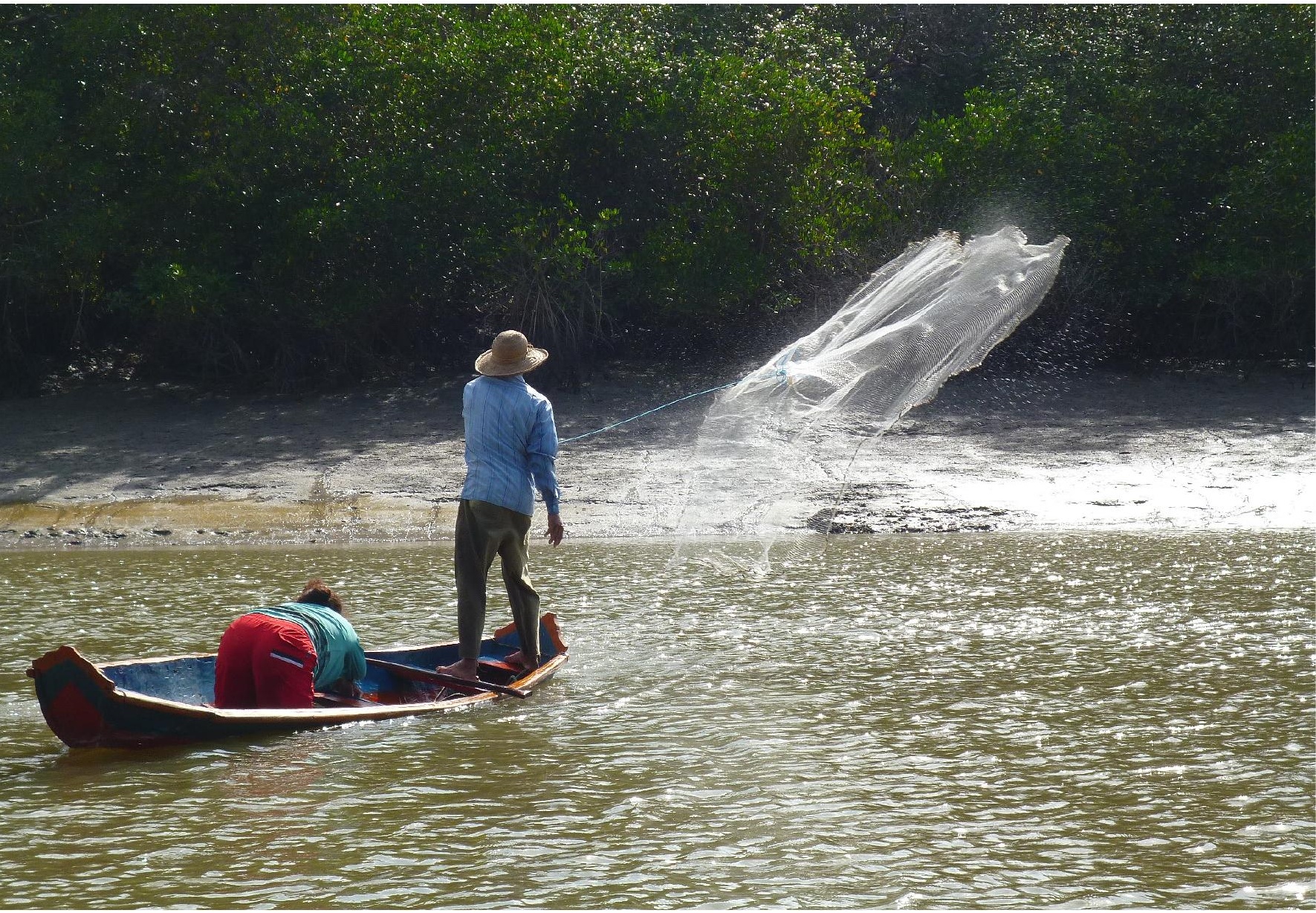

Figura 2 - Jogando a rede - Cultivo em Nazaré do Seco/Maracanã. 


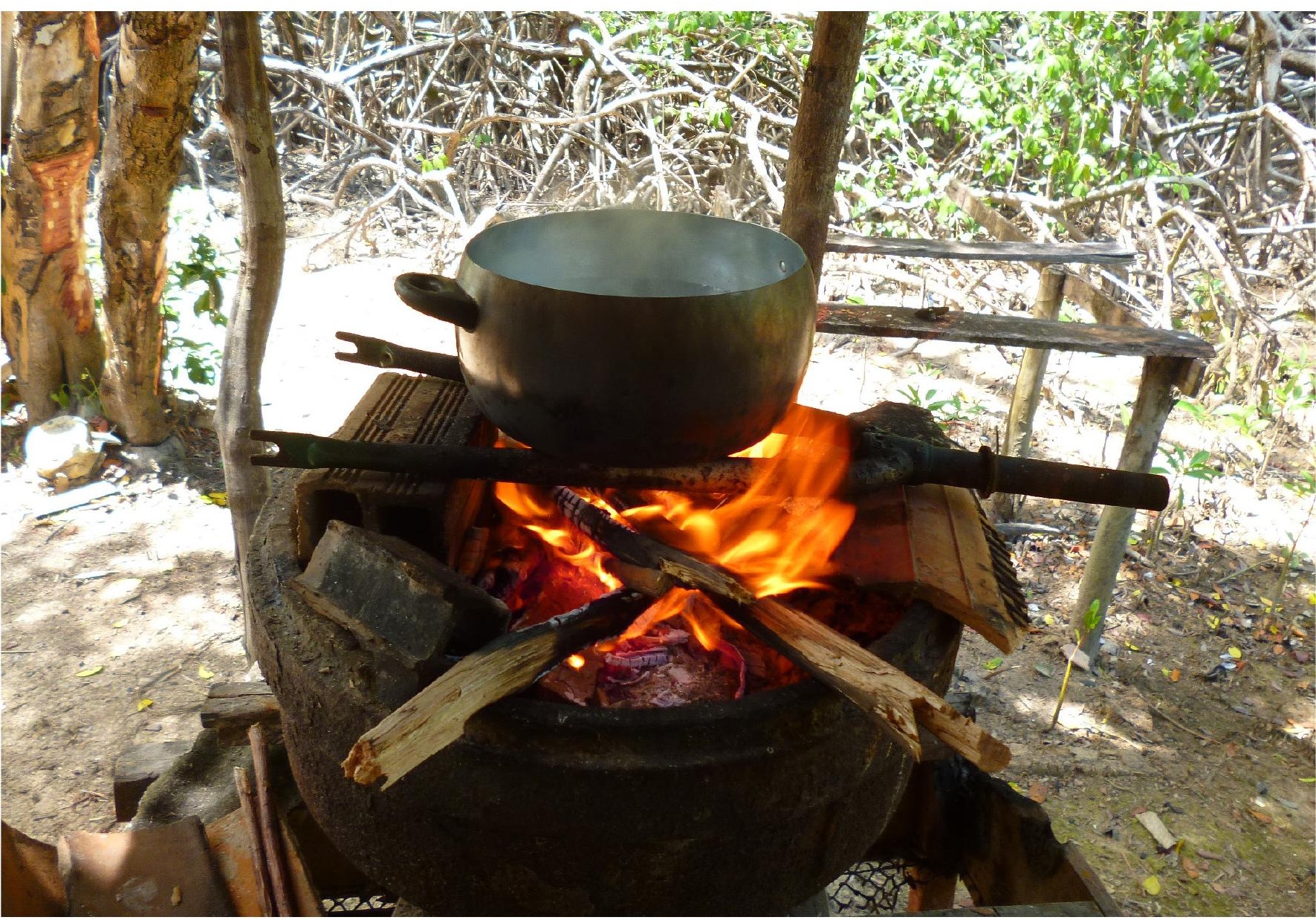

Figura 3 - Preparando a bóia - Cultivo em Alto Pererú/São Caetano de Odivelas. 
Sampaio, D. de S. | Beasley, C. R.

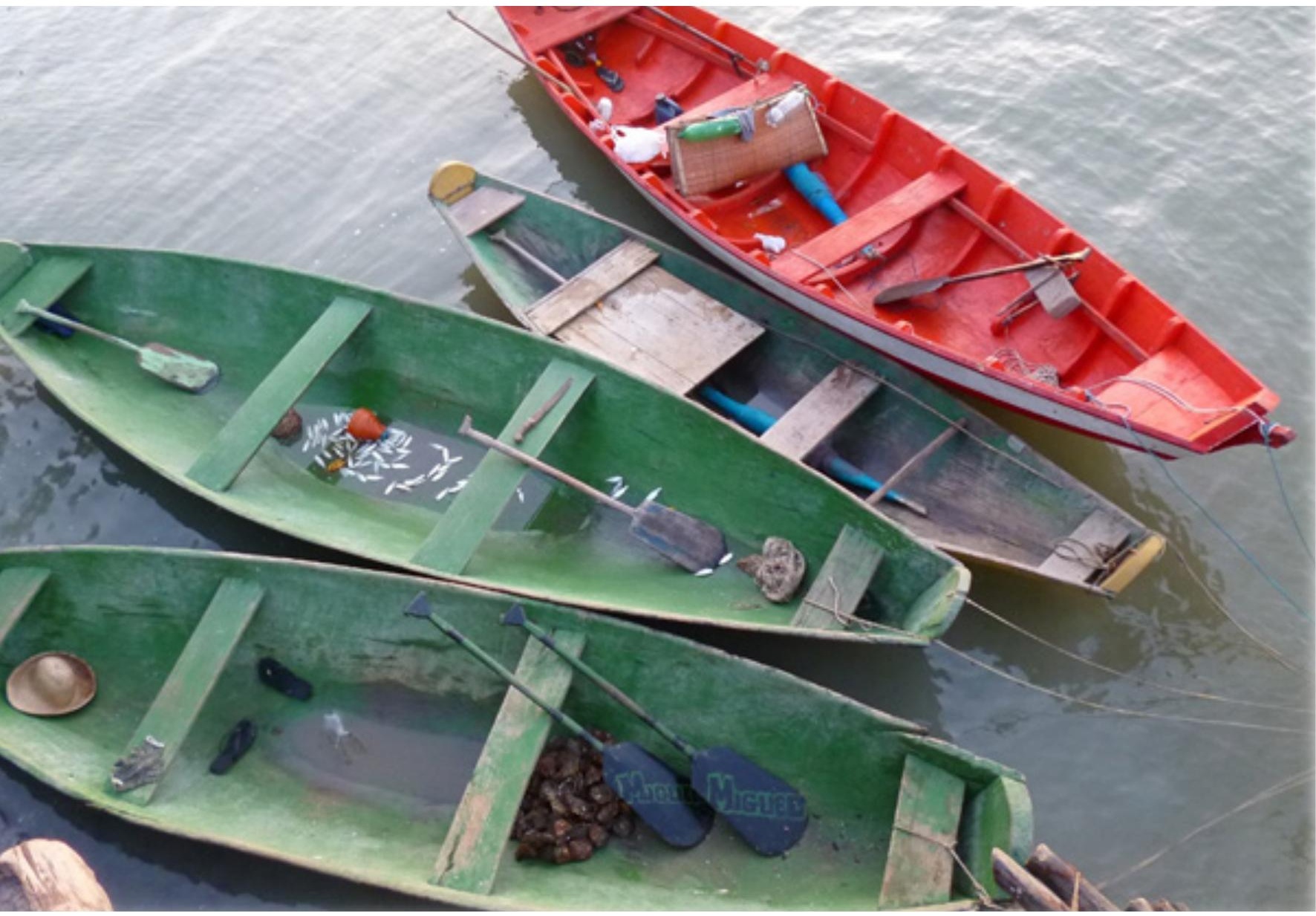

Figura 4 - Estacionamento montarias - Cultivo em Nova Olinda/Augusto Corrêa. 


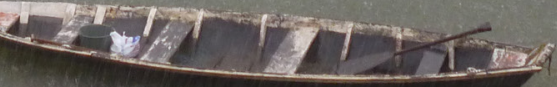

Figura 5 - Esperando a chuva passar - Cultivo em Lauro Sodré/Curuçá. 


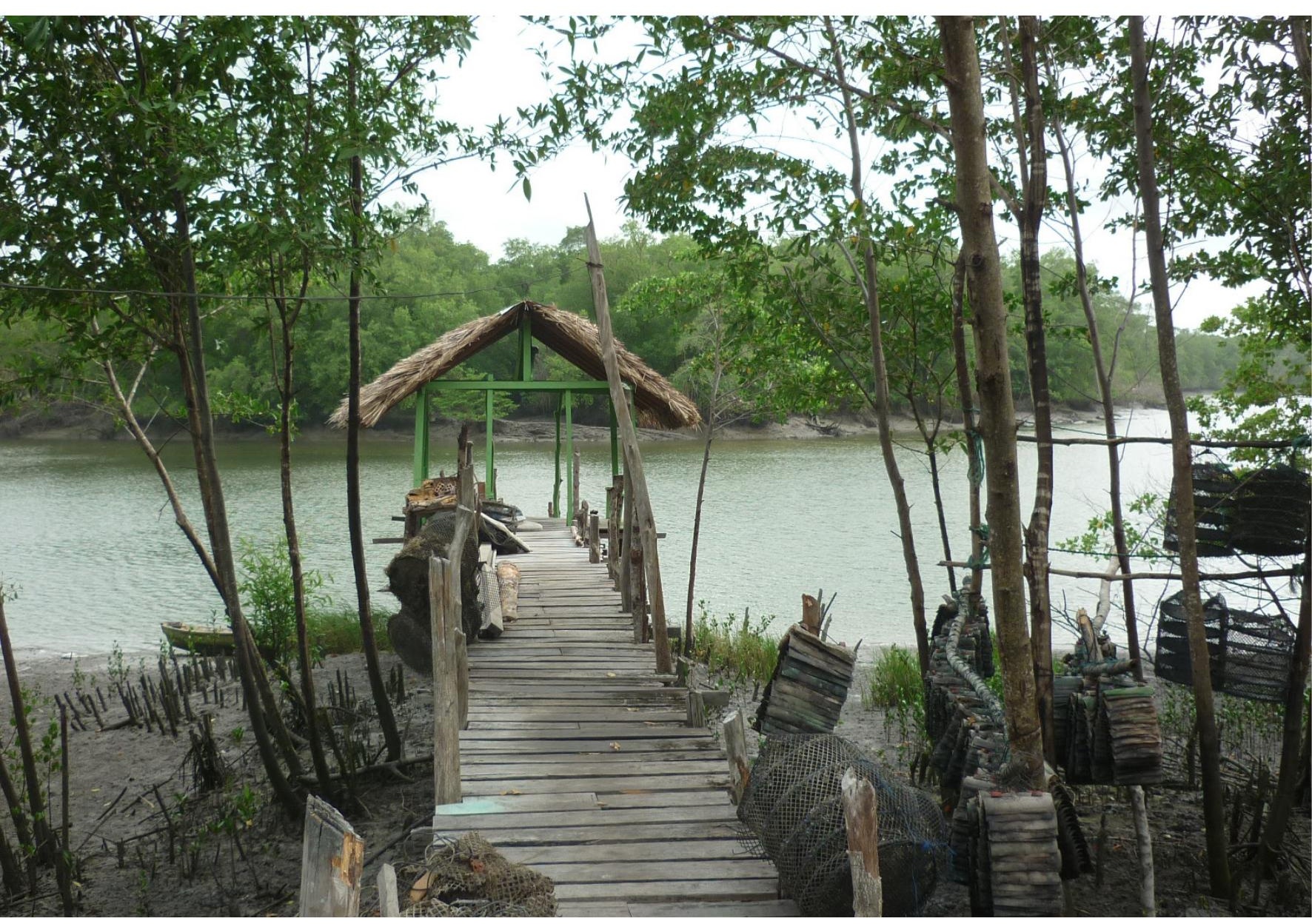

Figura 6 - A caminho do rancho - Cultivo em Santo Antônio de Urindeua/Salinópolis. 


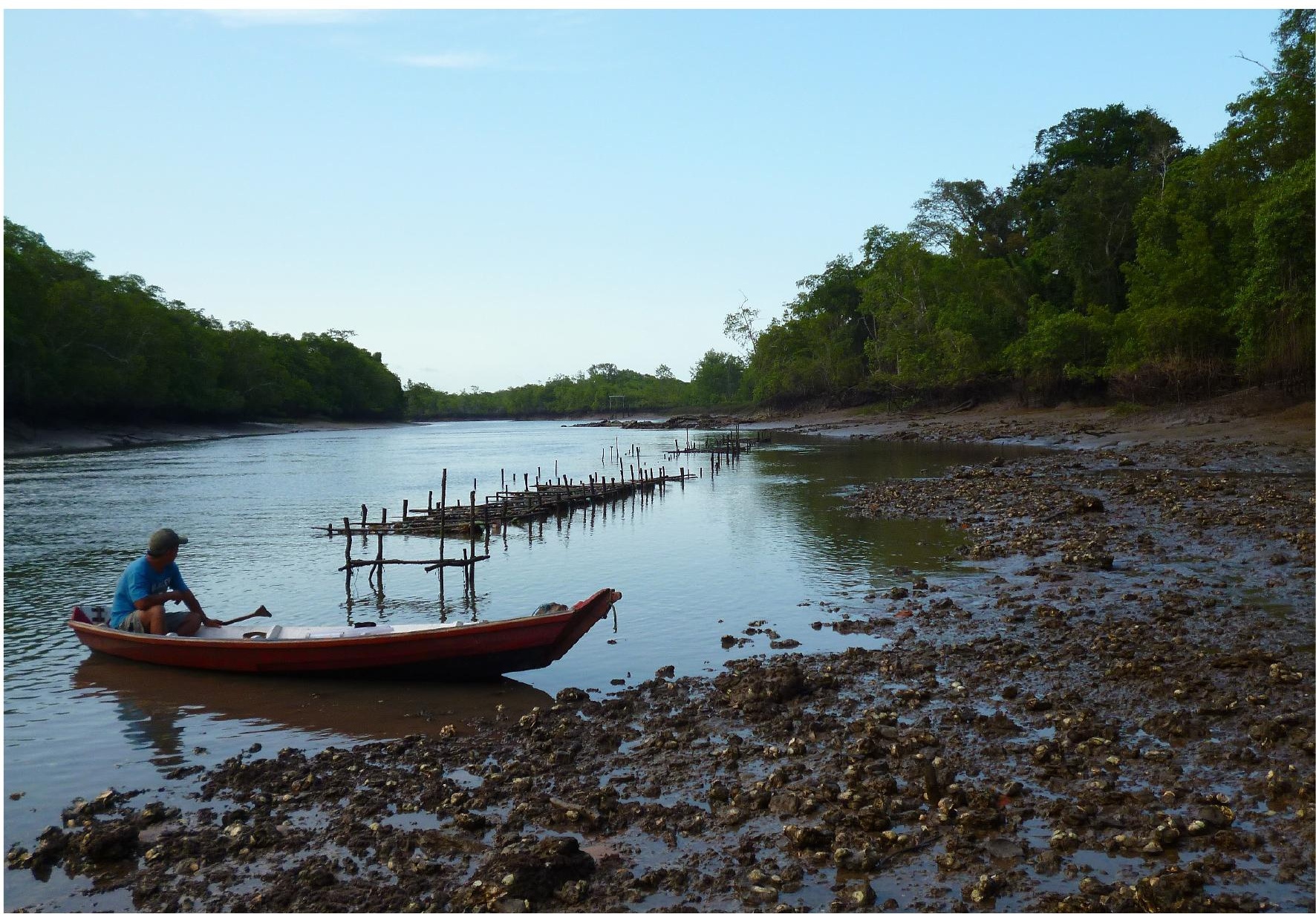

Figura 7 - Esperando a maré secar - Cultivo em Nazaré de Mocajuba/Curuçá. 


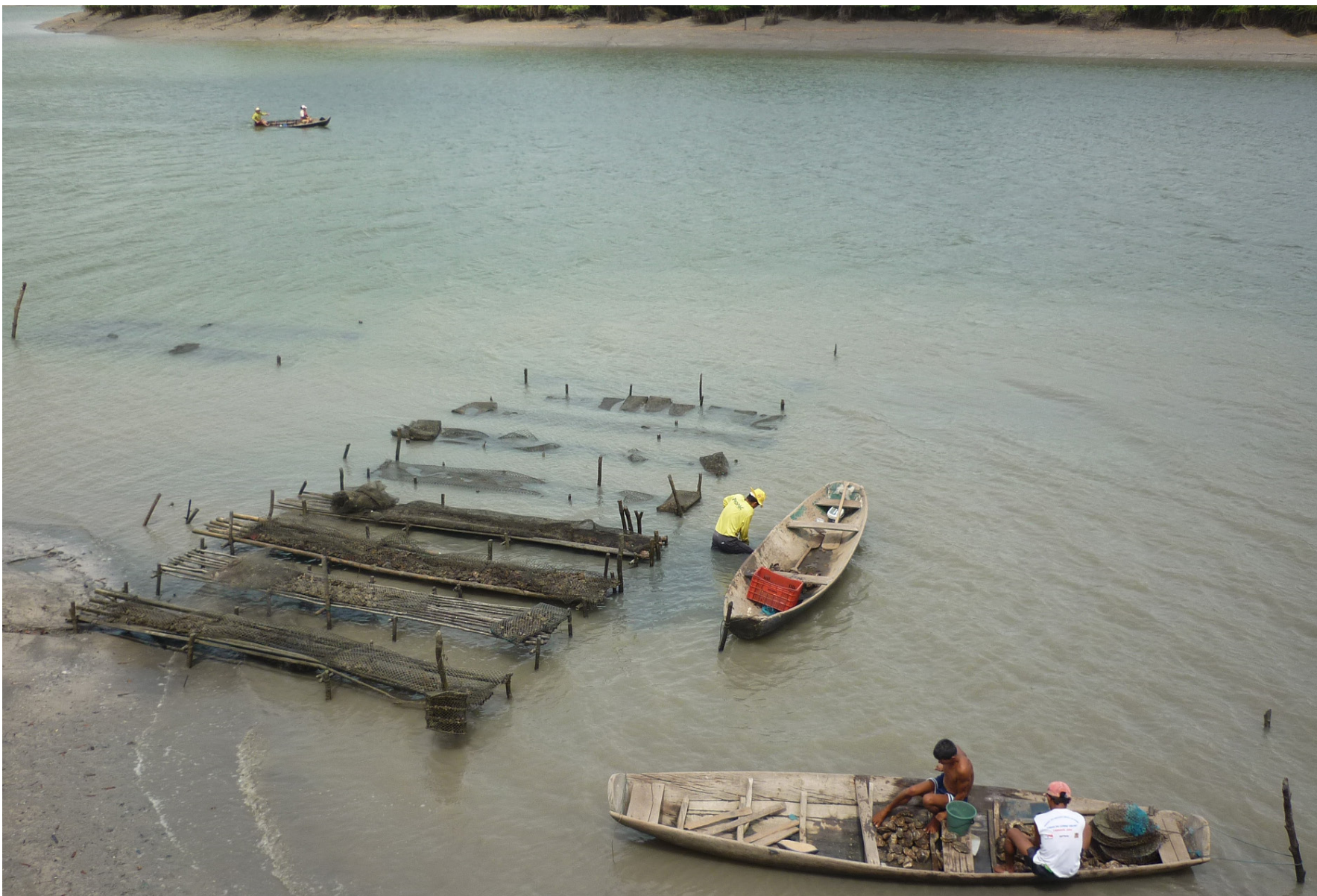

Figura 9 - Trabalho ... muito trabalho! - Cultivo em Nova Olinda/Augusto Corrêa. 
Sampaio, D. de S. | Beasley, C. R.

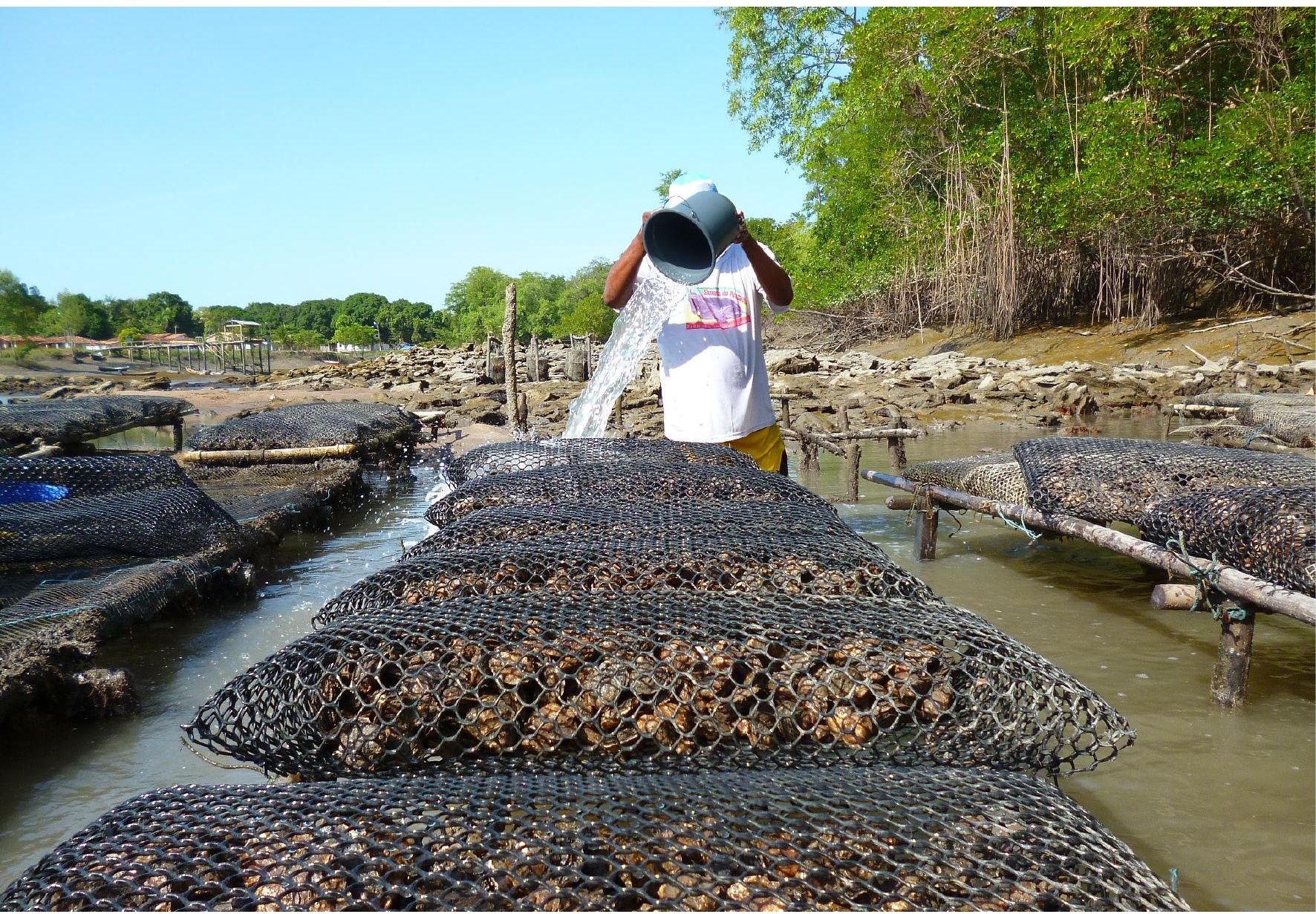

Figura 10 - Refrescando os travesseiros - Cultivo em Pererú de Fátima/São Caetano de Odivelas. 


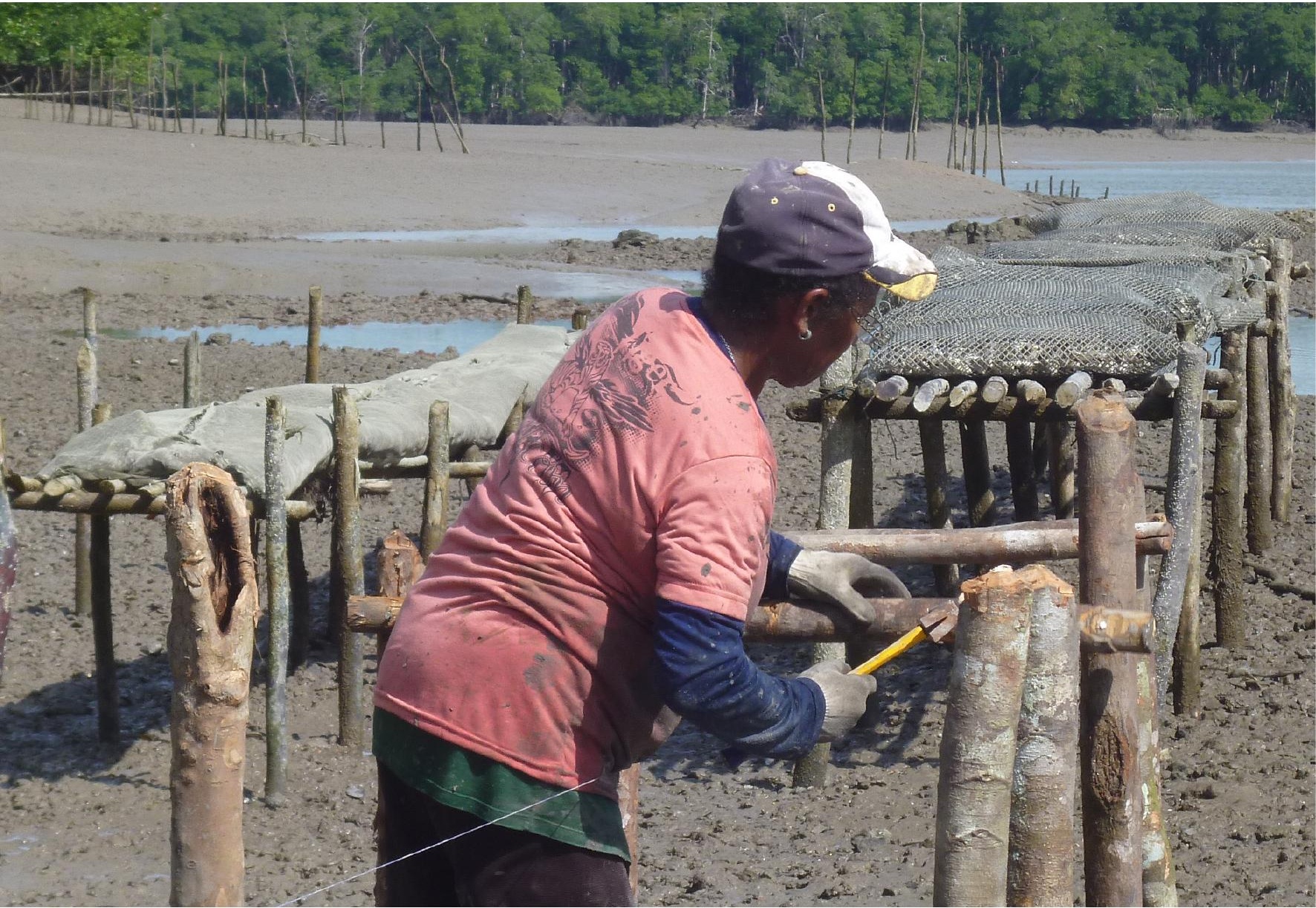

Figura 11 - Construindo as mesas de cultivo - Cultivo em Lauro Sodré/Curuçá. 


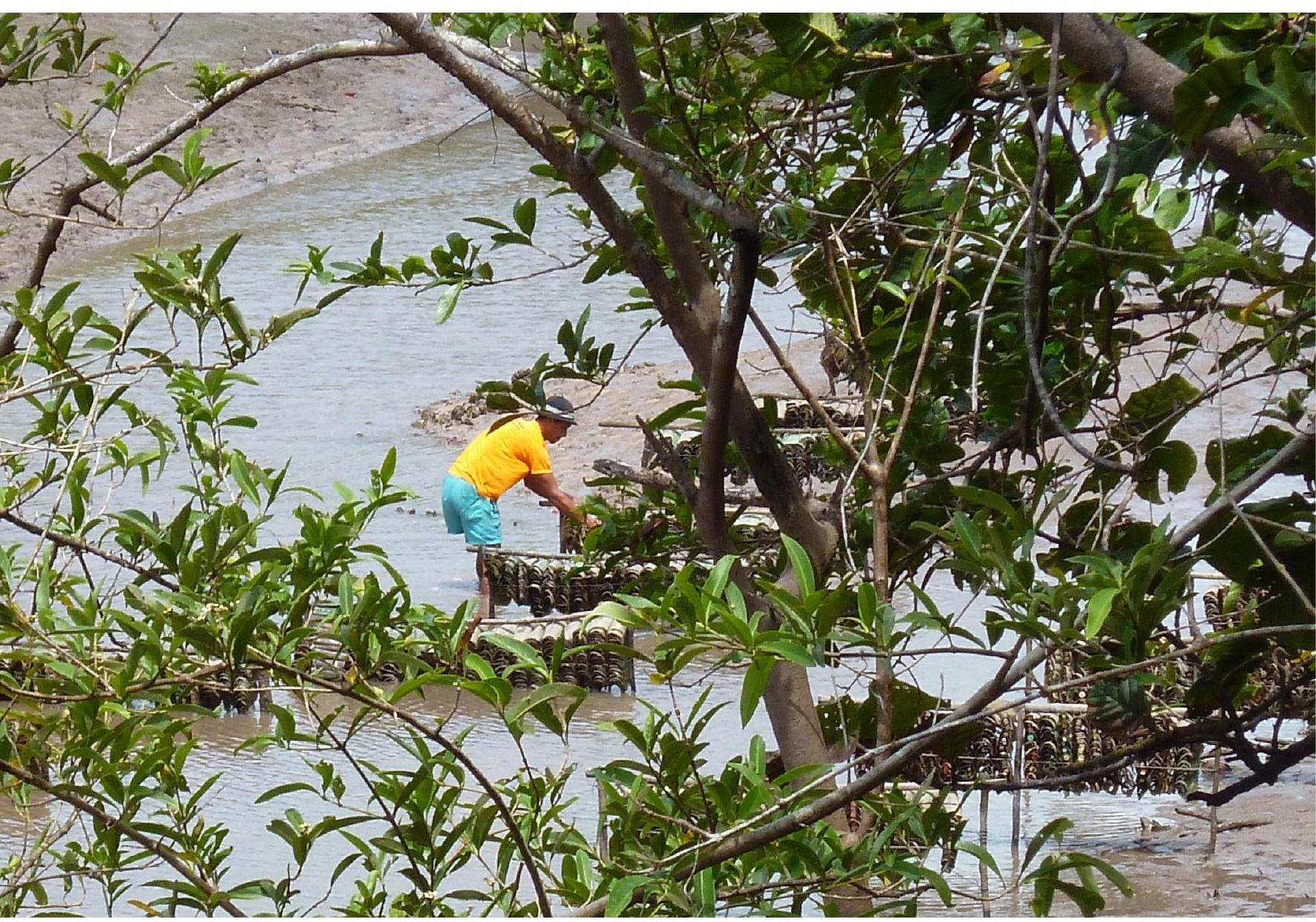

Figura 12 - Arrumando os coletores das sementes de ostras - Cultivo em Lauro Sodré/ Curuçá. 


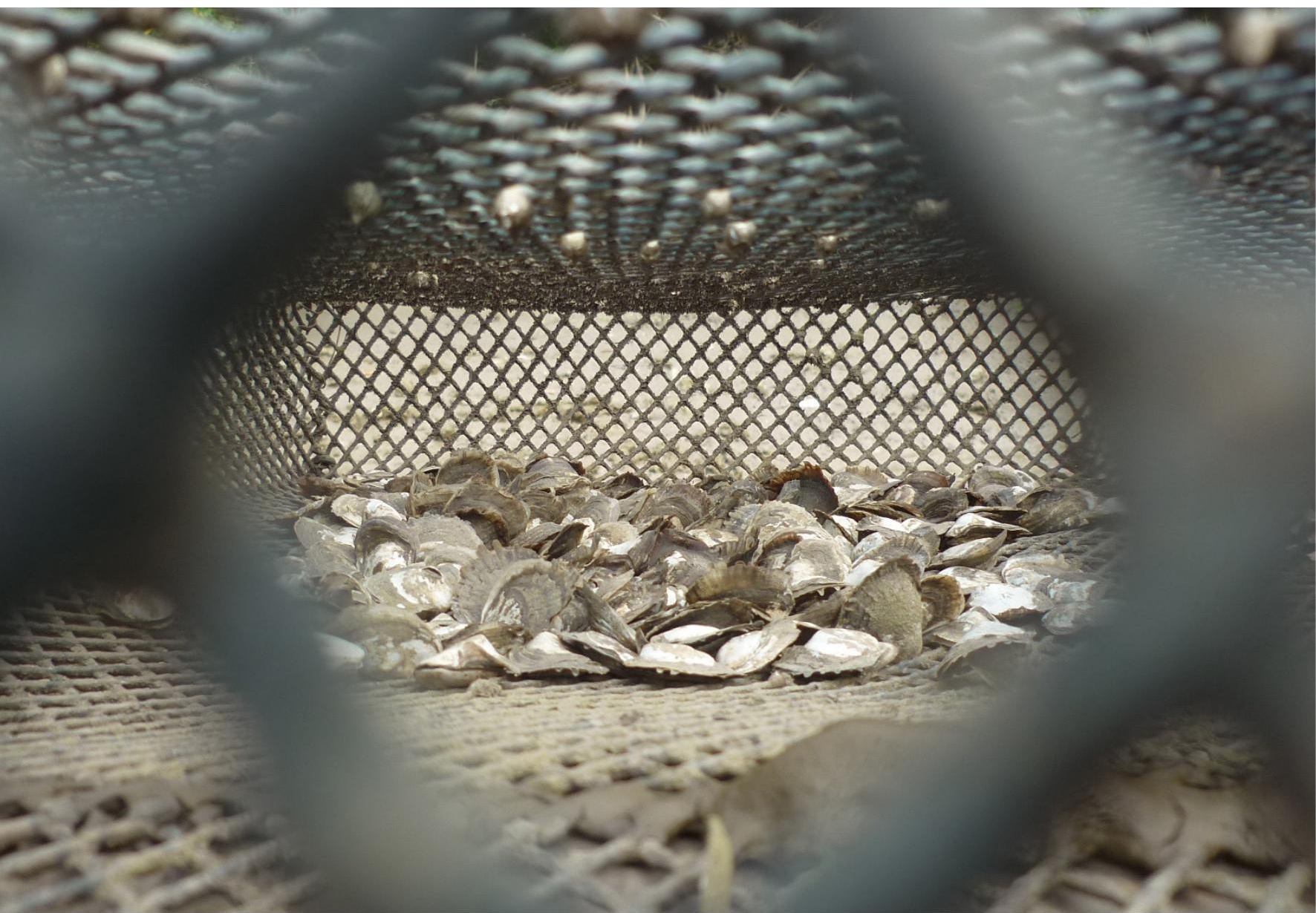

Figura 13 - Observando o crescimento - Cultivo em Pererú de Fátima/São Caetano de Odivelas. 
Sampaio, D. de S. | Beasley, C. R.

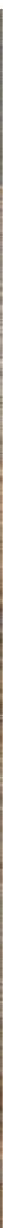

Figura 14 - Bom apetite! - Cultivo em Alto Pererú/São Caetano de Odivelas. 


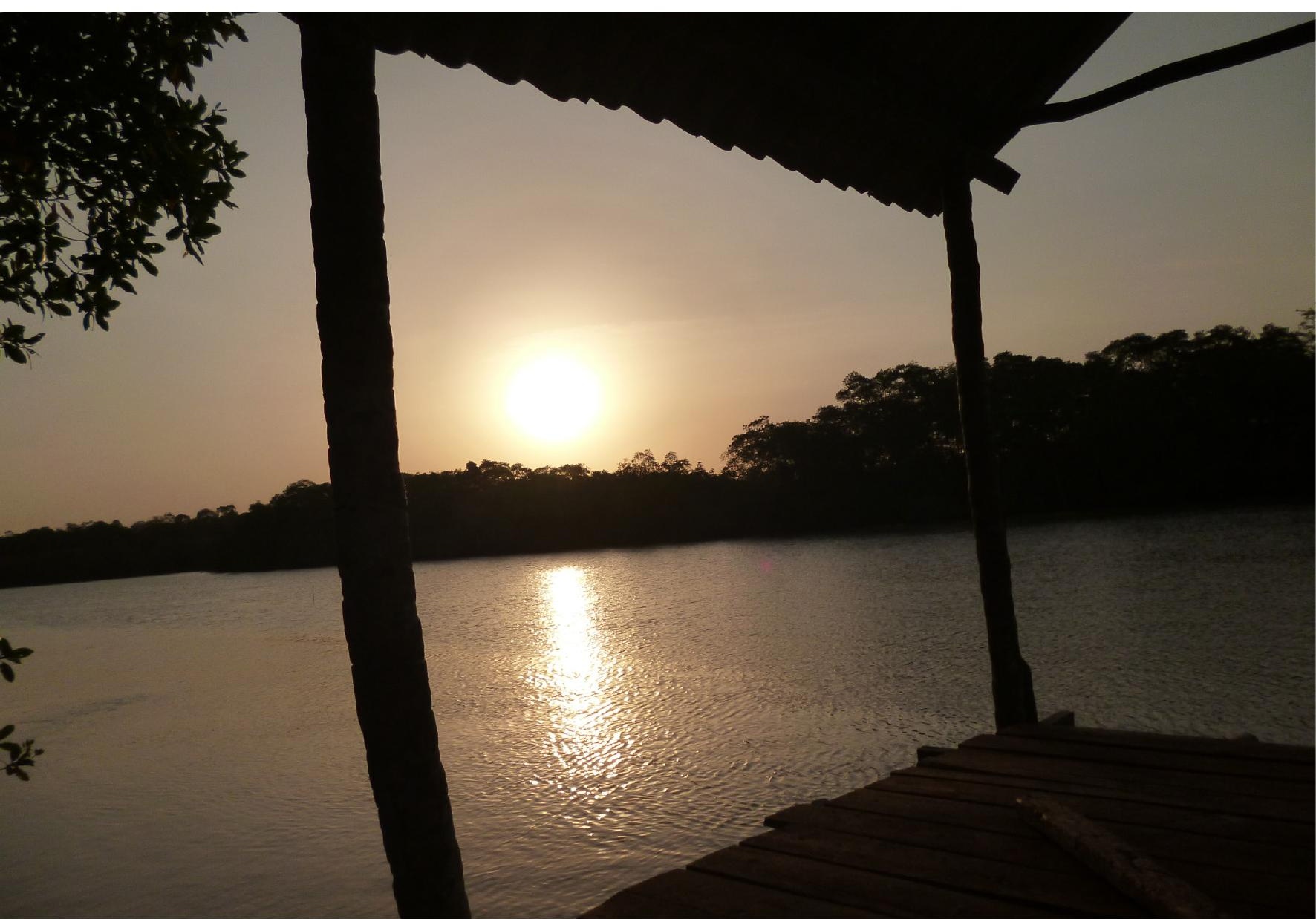

Figura 15 - Hora de descansar - Cultivo em Lauro Sodré/Curuçá. 